\title{
Members of the microRNA-200 family are promising therapeutic targets in cancer (Review)
}

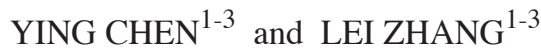 \\ ${ }^{1}$ Department of Gynecologic Oncology, Tianjin Medical University Cancer Institute and Hospital; ${ }^{2}$ Key Laboratory \\ of Cancer Prevention and Therapy; ${ }^{3}$ National Clinical Research Centre of Cancer, Tianjin 300060, P.R. China
}

Received January 18, 2016; Accepted February 10, 2017

DOI: $10.3892 /$ etm.2017.4488

\begin{abstract}
MicroRNAs (miRs) are non-coding, single-stranded RNA molecules that regulate gene expression at the posttranscriptional level. Abnormal expression of miR may result in pathophysiological processes occurring that stimulate the development of various diseases. miRs are commonly dysregulated in cancer and may act as either oncogenes or tumor suppressors. Studies have indicated that members of the miR-200 family are involved in different aspects of cancer biology, including the epithelial-to-mesenchymal transition, tumor angiogenesis and chemoresistance by targeting and repressing the expression of several key messenger RNAs. The present review aims to summarize the role of the miR-200 family and its potential mechanism of action in tumor progression, which may advance the development of novel therapeutic drugs against tumor metastasis in clinical cancer treatment.
\end{abstract}

\section{Contents}

1. Introduction

2. Studies of miR-200 family in human cancer

3. miR-200 family and tumor metastasis

4. miR-200 family and tumor angiogenesis

5. miR-200 family and chemosensitivity

6. Signals regulated by the miR-200 family in cancer

7. Future directions and concerns

\section{Introduction}

The landmark study of lin-4 in Caenorhabditis elegans identified a novel class of molecules called microRNA (miR), which are small non-coding RNAs consisting of 18-25 nucleotide

Correspondence to: Dr Ying Chen, Department of Gynecologic Oncology, Tianjin Medical University Cancer Institute and Hospital, Huanhuxi Road, Tianjin 300060, P.R. China

E-mail: lychenying2004@126.com

Key words: microRNA, microRNA-200, cancer, epithelial-tomesenchymal transition base pairs (1) These small nucleic acids regulate gene expression by binding to the $3^{\prime}$ untranslated region (3'-UTR) of mRNA, resulting in translational repression or transcript degradation (2). Over 2,500 miRs have been identified in the human genome since their discovery in 1993 and it has been determined that $30-50 \%$ of genes that code for proteins are controlled by miR in humans (3). Thus, miRs have emerged as integral components of various biological processes, including cell proliferation, migration, differentiation, apoptosis and angiogenesis (4). It has been demonstrated that the altered expression of $\mathrm{miR}$ is associated with tumorigenesis and the progression of different types of cancer $(5,6)$. By regulating multiple potential target genes, miR expression may lead to pathological changes in cells, ultimately contributing to the development of cancer (7).

One particular family of miR, the miR-200 family, has been identified to be crucial in tumorigenesis. Members of the miR-200 family are downregulated in aggressive human tumors and target different signaling pathways including the Notch, Wnt and transforming growth factor $\beta$ (TGF- $\beta$ ) pathways, thus inhibiting migration, tumor cell adhesion, epithelial-to-mesenchymal transition (EMT) and angiogenesis $(8,9)$. The present review will focus on summarizing the roles of the miR-200 family as putative tumor suppressors in tumor progression and propose that the restoration of miR-200 expression may have therapeutic implications for the clinical treatment of metastatic and drug-resistant tumors.

\section{Studies of miR-200 family in human cancer}

The miR-200 family consists of five members (miR-200a, $-200 b,-200 c,-141$ and -429), which are clustered and expressed as two separate polycistronic pri-miR transcripts (miR-200b-200c-429 and miR-200a-141) located on human chromosomes 1 and 12, respectively (10). miR-200b, -200c and -429 contain AAUACUG as their seed sequences, whereas miR-200a and -141 possess AACACUG (11). Due to the similarity of their seed sequences, they may have similar target genes (Table I). A series of studies using superior profiling technologies, such as a combination of miRNA expression arrays, quantitative polymerase chain reaction assays and mass spectrometry DNA methylation analysis, have indicated that the miR-200 family is aberrantly expressed in different types of cancer. Multiple studies utilizing different detection 
Table I. Chromosomal localization and sequences of the miR-200 family.

\begin{tabular}{llc} 
miR & Sequences (5'-3') & Chromosomal localizatio \\
\hline hsa-miR-200b & UAAUACUGCCUGGUAAUGAUGAC & Chromosome 1p36 \\
hsa-miR-200c & UAAUACUGCCGGGUAAUGAUGG & Chromosome 1p36 \\
hsa-miR-429 & UAAUACUGUCUGGUAAAACCGU & Chromosome 1p36 \\
hsa-miR-200a & UAACACUGUCUGGUAACGAUGU & Chromosome 12p13 \\
hsa-miR-141 & UAACACUGUCUGGUAAAGAUGG & Chromosome 12p13
\end{tabular}

miR, microRNA.

platforms, which compared extensive sets of tumor tissues and cell lines to large sets of normal control samples, identified that the differential expression of members of the miR-200 family serves an important role in combating tumor cell invasion, EMT and metastasis $(8,12)$. Furthermore, numerous studies have demonstrated that members of the miR-200 family may be associated with pathogenesis and disease prognosis (12-28) (Table II). Therefore, the miR-200 family has the potential to become a novel class of biomarker for tumor prognosis and targets of novel drugs against tumor progression.

\section{3. miR-200 family and tumor metastasis}

Different types of miR become deregulated in tumors as a result of various mechanisms, including miR-200c deregulated in ovarian cancer and miR-21 deregulated in breast cancer $(29,30)$. Genomic abnormalities, including deletion, amplification and translocation, are common in tumorigenesis, and miR expression may also be affected by transcriptional and post-transcriptional regulation (7). Many pri-miR are either oncogenes or tumor suppressors and are induced by transcription factors (7). It has been demonstrated that various transcription factors including p53, c-Myc and E2 transcription factor (E2F), are closely associated with miR in cancer (31). The processing and stability of miR are also important factors determining miR expression. Additionally, levels of Dicer or Drosha expression, the miR processing machinery, are altered and transformed in various types of cancer, possibly due to the increase in the copy number of $\mathrm{miR}$ (32).

Metastasis is an important characteristic of malignant tumors and EMT is the initial step of metastasis. The miR-200 family inhibits EMT and maintains the epithelial phenotype by directly targeting the transcriptional repressors of E-cadherin [zinc finger E-box-binding homeobox (ZEB)1 and ZEB2] (33).

The primary step and important characteristics of tumor metastasis are the disassembly of tight junctions and loss of apical-basal polarity among cancer cells (8). The loss of epithelial markers and the gain of mesenchymal morphological features in cancer cells contributes to the suppression of the transmembrane adhesion receptor E-cadherin and a gain in the expression of mesenchymal markers, including vimentin, collagen, fibronectin, and the E-cadherin transcriptional repressors ZEB1 and ZEB2 (also known as SMAD-interacting protein 1) (9). These vital molecules cause the extracellular matrix-induced stimulation of the integrin signal pathway, resulting in focal adhesion formation, which facilitates cancer cell migration, invasion and metastasis (8). The transcriptional factors ZEB1 and ZEB2 induce EMT by repressing the expression of E-cadherin and promoting cancer cell migration, invasion and metastasis (9). TGF- $\beta$ also serves an important role in the EMT in epithelial cells as it commands cell proliferation and differentiation during the process of embryonic development or cancer progression (34).

\section{4. miR-200 family and tumor angiogenesis}

It is widely accepted that angiogenesis, the formation of new blood vessels from pre-existing ones, is a fundamental process required for cancer development and growth (26). Without angiogenesis, cancer cells inside the tumor undergo apoptosis. The angiogenesis switch depends on the balance of angiogenesis activators and inhibitors. The activation of angiogenesis is initiated when pre-existing vessels become permeable in response to stimulating factors, including vascular endothelial growth factor (VEGF), placental growth factor and angiopoietin-1 (35). VEGF is considered to be the most well known fundamental factor and modulator of angiogenesis. VEGF combined with its receptors [fms-like tyrosine kinase 1 (flt1) or VEGF receptor (VEGFR)-1 and kinase-insert domain containing receptor (KDR) or VEGFR-2], stimulates endothelial cell migration, proliferation and survival (36). As angiogenesis is essential for tumor growth, inhibiting VEGF signaling using strategies such as small interfering RNA, small molecule inhibitors, antibodies and VEGF-traps is a promising therapeutic approach for cancer treatment. Furthermore, research has demonstrated that miR-200 family members are involved in the regulation of vascular development and angiogenesis by downregulating VEGF signaling (37). By using a clear cell renal cell carcinoma and matched normal kidney sample, Liu et al (38) identified a negative correlation between VEGF and the miR-200 family. Choi et al (39) demonstrated that VEGF and its receptors, Flt1 and KDR, were the key participants in the VEGF signal pathway and were negatively regulated by miR-200b, which directly targeted the 3'-UTR of those genes. Tube formation and phosphorylation of extracellular signal-regulated kinases $1 / 2$ were inhibited if miR-200b was transected into human umbilical vein endothelial cells, suggesting that miR-200b has anti-angiogenic activity (39). 


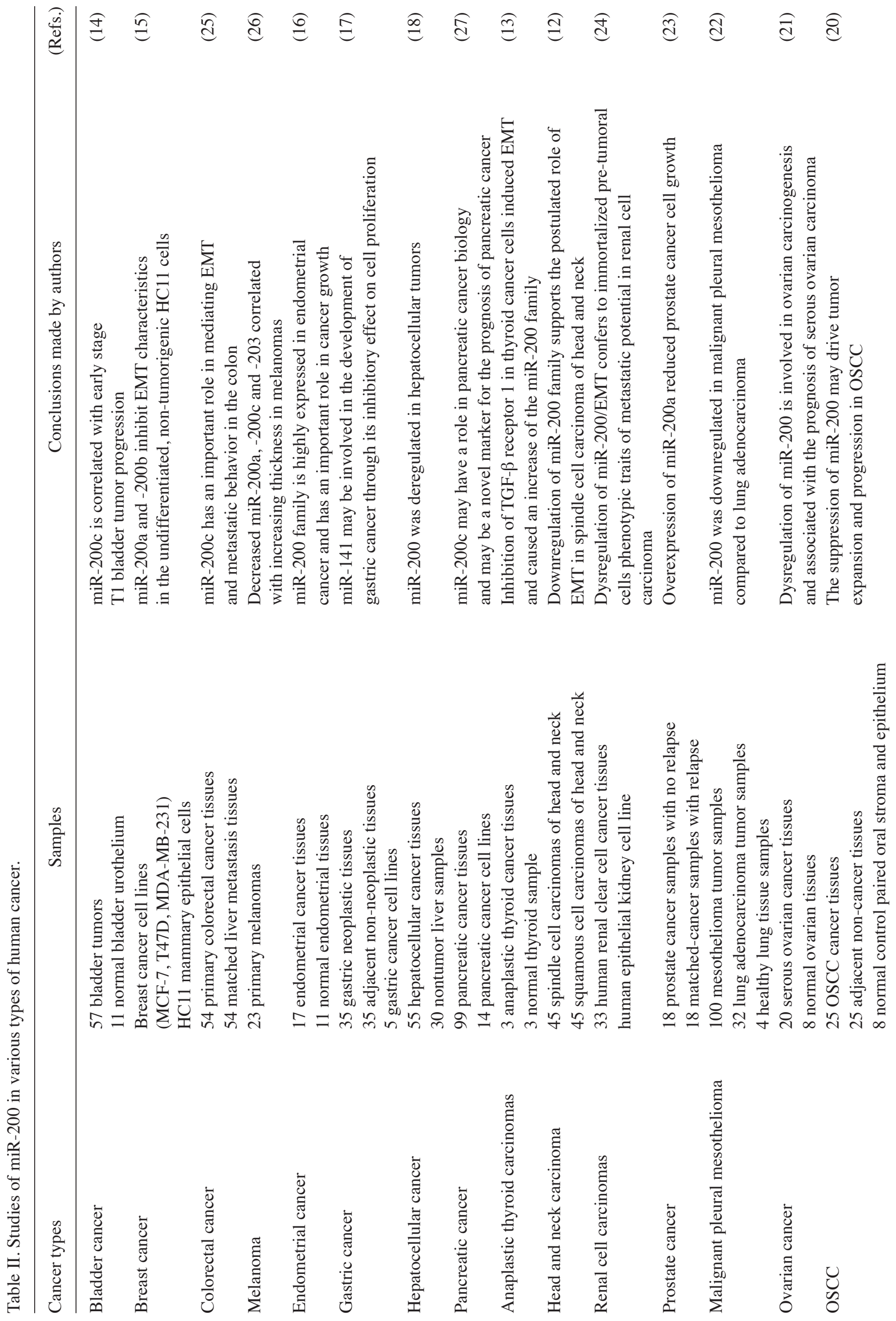


Furthermore, it is understood that intratumoral ligands establish a complex network of cell-cell interactions within the tumor microenvironment. Roybal et al (40) determined that Flt1/VEGFR1 was a candidate miR-200 target gene. Overexpression of miR-200 inhibited angiogenesis in metastasis-prone lung adenocarcinoma cells derived from $K$-ras/p53-mutant mice by inhibiting angiogenesis, thus decreasing Flt1 levels (40). These results indicate that lung adenocarcinomas with low levels of miR-200 expression may be responsive to treatment with anti-VEGF agents (40). In some chronic non-cancer non-healing diseases, Chan et al (41) reported that hypoxia inhibited miR-200b expression in human dermal microvascular endothelial cells, thus promoting angiogenesis. Furthermore, it was identified that downregulation of endothelial miR-200b is crucial in stimulating cutaneous wound angiogenesis by attenuating the repression of GATA binding protein 2 and VEGFR2 expression (42). These results identified that GATA2 was a target of miR-200b, which provided novel insight regarding the regulation of wound angiogenesis by miR-200 and the significance of such regulation in the context of chronic cutaneous wounds (42). Additionally, it was demonstrated that in lung, renal, ovarian and basal-like breast cancer, miR-200 inhibits angiogenesis via direct and indirect mechanisms by targeting interleukin- 8 and $\mathrm{C}-\mathrm{X}-\mathrm{C}$ motif chemokine ligand 1 secretion by tumor endothelial cells (43). Thus, the miR-200 family may provide a potential anti-angiogenesis therapy to treat cancer and other diseases dependent on angiogenesis, as inhibition of VEGF signaling interferes with angiogenesis.

\section{5. miR-200 family and chemosensitivity}

Chemotherapy drug resistance often inhibits the clinical treatment of cancer, resulting in a poor prognosis for patients with cancer. MiR-200 family members are involved in maintaining sensitivity to microtubule targeting agents and DNA damaging drugs, which are two classes of chemotherapeutics (44). Gibbons et al (34) identified an association between miR expression and cancer chemosensitivity in cholangiocarcinoma. It has been demonstrated that miR-2 1 and $-200 \mathrm{~b}$ are involved in the regulation of tumor cell sensitivity to gemcitabine by targeting specific genes, including Circadian Locomotor Output Cycles Kaput, phosphatase and tensin homolog and protein-tyrosine phosphatase $1 \mathrm{~B}$, as well as downstream oncogene products, including c-Abl, Src and Ras $(34,45)$. Furthermore, it has been suggested that there are similarities between drug-resistant cancer cells and enhanced invasiveness or metastasis, which is consistent with the dysregulation of miR-200 in drug resistant cancer cells $(34,44,45)$. For example, decreased expression of miR-200b and $-200 \mathrm{c}$ has been observed in the acquired cisplatin resistant phenotype of MCF-7 human breast adenocarcinoma cells (46). It was reported that aberrant miR expression participated in the regulation of cell survival, cell conductive signaling, invasiveness and DNA methylation, implying that abnormal miR expression was associated with the unusual activity of cellular processes in cisplatin-resistant breast cancer cells (46). In a study investigating miR expression profiles, the expression of miR-200b was significantly downregulated in a docetaxel-resistant human non-small cell lung cancer (NSCLC) cell line (SPC-A1/docetaxel) compared 


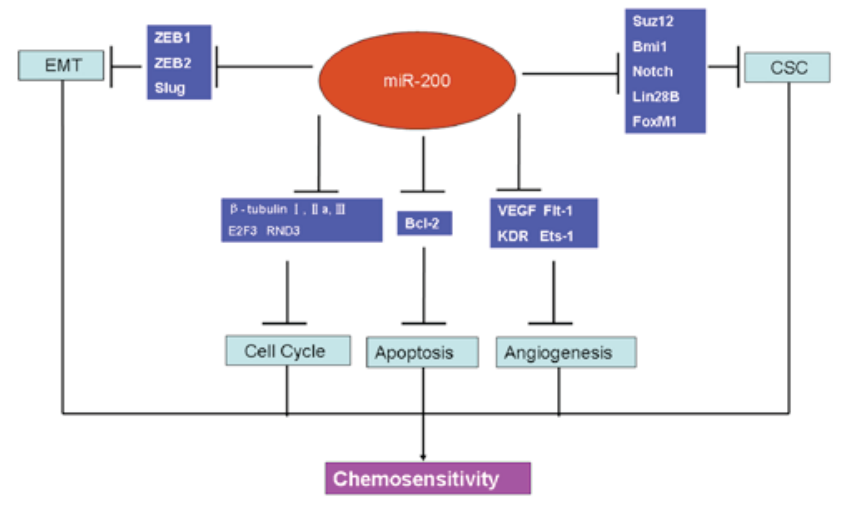

Figure 1. Targets of miR-200 involved in cancer chemoresistance. The verified targets of miR-200 are associated with cancer chemosensitivity through EMT, the cell cycle, apoptosis, angiogenesis and CSC maintenance. miR, microRNA; EMT, epithelial-to-mesenchymal transition; CSC, cancer stem cell; ZEB, zinc finger E-box-binding homeobox; E2F3, E2F transcription factor 3; RND3, Rho family GTPase 3; Bcl-2, B-cell lymphoma 2; VEGF, vascular endothelial growth factor; Flt-1, fms-like tyrosine kinase 1; KDR, kinase-insert domain containing receptor.

with a control SPC-A1 cell line (47). The results suggested that measuring miR-200b expression may provide an explanation for drug sensitivity or resistance in docetaxel-resistant cells in patients with NSCLC (47). Additionally, Chen et al (48) demonstrated that restoring expression of miR-200b was able to reverse chemoresistant phenotypes of docetaxel-resistant cells in human lung adenocarcinoma (LAD) by targeting E2F transcription factor 3 using histone deacetylase (HDAC) inhibitors. These findings suggest that the HDAC1/miR-200b/E2F3 signal pathway may be responsible for chemoresistance in docetaxel-resistant LAD cells (48). Furthermore, members of the miR-200 family may be potential therapeutic targets for disseminated or chemoresistant cancer cells in ovarian cancer (49).

miR-200 family members serve a vital role in regulating cancer chemosensitivity. The association between miR-200 and cancer chemoresistance may be explained by a number of factors, including EMT, cancer stem cell (CSC) maintenance, apoptosis, angiogenesis and cell cycle distribution (Fig. 1). It has been demonstrated that miR-200 family members are critical determinants in the EMT process via targeting ZEB transcription factors $(11,50,51)$. Following this, the expression of clusters of genes, including E-cadherin and vimentin, were controlled (11,50,51). CSCs are defined as a small population of cells that possess the capacity of self-renewal and generate differentiated progeny in tumors. The acquisition of an EMT phenotype and the induction of CSC phenotypes have biological functions in common and these similarities synergistically contribute to cancer chemoresistance. Thus, the properties of CSCs partly gave rise to EMT in cancer metastasis.

It is widely understood that angiogenesis is essential for tumor progression. VEGF is a fundamental regulatory molecule in tumor angiogenesis and VEGF function may be reduced by the use of antiangiogenic agents to inhibit VEGFR, which means that reducing VEGF function may result in a decrease in interstitial fluid pressure and improved blood vessel morphology recovery (52). Therefore, decreased tumor blood supply combined with lower chemotherapy drug delivery may reduce the sensitivity of cancer cells to chemotherapy, resulting in the development of chemoresistance. The B-cell lymphoma 2 ( $\mathrm{Bcl}-2)$ protein family is associated with multi-drug resistance (53). One of the most important and common features of tumor cells is resistance to apoptosis signaling, which generates multi-drug resistance (53). The miR-200 family is able to reduce resistance to apoptosis and drugs in cancer cells by targeting Bcl-2 (54). Furthermore, Bcl-2 expression was reduced by miR-200 in gastric carcinoma, which led to enhanced apoptosis (54). Chemotherapy resistance is mediated by the cell cycle, and sensitivity to drugs or agents in cancer treatment may be attributed to the stage of the cell cycle in which the cells are (55). The miR-200 family may affect cell cycle distribution by targeting $\beta$-tubulin, E2F3 or Rho family GTPase $3(55,56)$.

\section{Signals regulated by the miR-200 family in cancer}

The signaling of EMT is considered to be active throughout tumorigenesis and tumor progression. It has been demonstrated that overexpression of miR-200 inhibits the capacity of tumor cells to undergo invasion and metastasis, highlighting the role of miR-200 in the regulation of EMT and subsequent metastasis (57). Notch signaling is a crucial pathway involved in embryogenesis and is responsible for the self-renewal abilities of embryonic stem cells (58). In various solid tumors, including lung, pancreatic, breast carcinoma and malignant melanoma, aberrant activation of Notch signaling is frequently observed (58). Mechanistic studies supporting that Notch signaling serves a crucial role in regulating EMT and metastasis during cancer progression have also identified that miR-200 decreases expansion of human metastatic prostate cancer cells by targeting the Notch ligand, jagged (JAG) 1, and the mastermind-like transcriptional coactivators (Maml) 2 and $3(58,59)$ Additionally, the Notch ligand JAG2 was able to inhibit miR-200 family expression at the transcriptional level by inducing GATA transcription factors, thus stimulating tumor progression (60).

It has been determined that TGF- $\beta$, a profibrotic cytokine, is the primary pathogenic driver in tubular epithelial cells and is able to induce EMT (61). The pathway of TGF- $\beta /$ SMAD signaling is considered to be a classical pathway that induces EMT. This inhibits tumor development at the early stage of cancer, yet promotes tumor progression at the advanced stages of cancer (61). miR-200 family members suppress TGF- $\beta /$ SMAD signaling, promote epithelial gene expression and suppress cell invasion by regulating a network of genes (61). In a study on gastric cancer, miR-200 was downregulated by $\mathrm{CpG}$ island methylation and TGF- $\beta$ signaling, which increased Zeb1/2 expression and decreased E-cadherin expression to promote cancer cell migration and invasion, providing powerful evidence supporting the application of decitabine in clinical cancer treatment as decitabine inhibits methylation (62).

The complicated mutual transcriptional regulation of feedback $\mathrm{ZEB} / \mathrm{miR}-200$ loops and TGF- $\beta$ signaling is involved in the interaction between ZEB and TGF- $\beta$ protein $(13,63)$. The mechanisms of the autocrine TGF- $\beta / \mathrm{ZEB} / \mathrm{miR}-200$ loop signaling regulatory network to control cell plasticity between the epithelial and mesenchymal states may include: i) The regulation of ZEB2 transcription induced by TGF- $\beta$ 


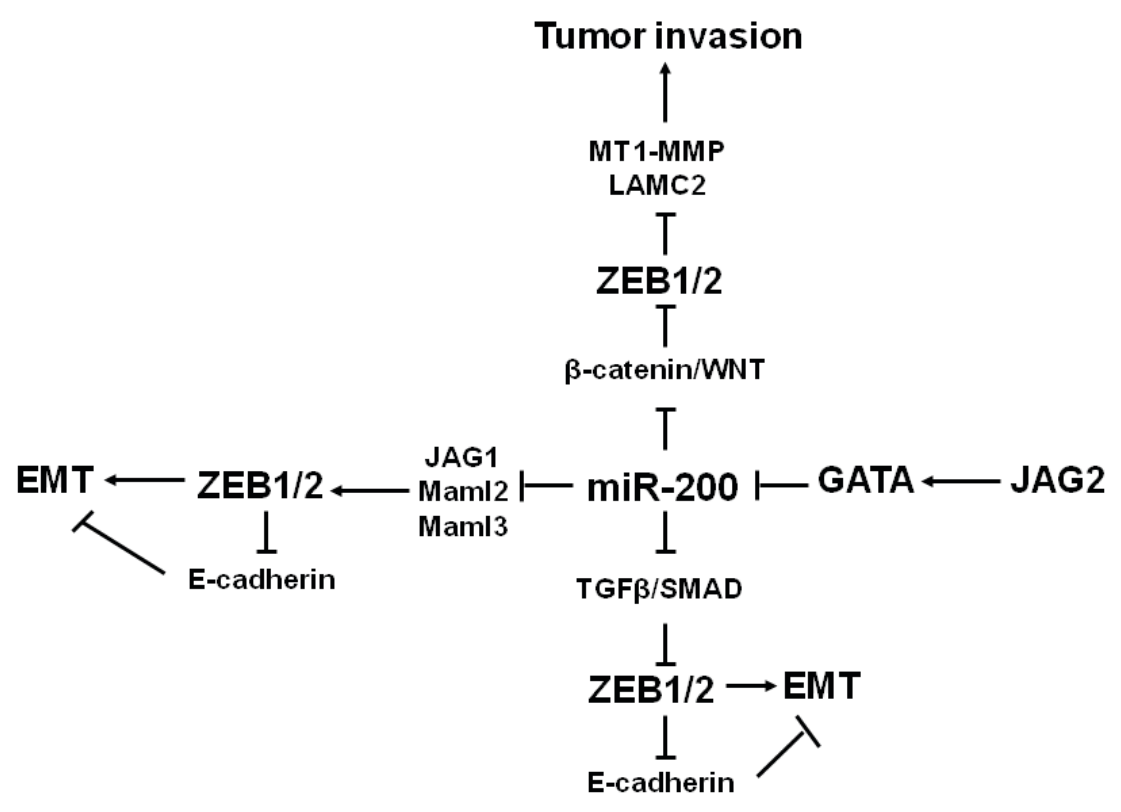

Figure 2. miR-200/ZEB and cancer-associated signaling pathways. miR, microRNA; ZEB, zinc finger E-box-binding homeobox; EMT, epithelial-to-mesenchymal transition; Maml, mastermind-like transcriptional coactivators; TGF, transforming growth factor; JAG, jagged; MT1-MMP, membrane-type 1 matrix metalloproteinase; LAMC2, laminin gamma chain 2.

by SMAD, which may be directly targeted by the ZEB2 gene promoter in vivo $(13,63)$ and ii) the suppression of miR-200 loci was recovered by reversible DNA methylation of ZEB proteins participating in the process of recruitment of histone-modifying complexes (64).

Furthermore, it has been demonstrated that Wnt signaling is functionally correlated with the $\mathrm{ZEB} / \mathrm{miR}-200$ loop in tumors (65). A functional conserved miR-200a-binding site is contained in the $3^{\prime}$ UTR of $\beta$-catenin mRNA, meaning that miR-200a is able to directly target and bind to this position to suppress the $\beta$-catenin/Wnt signaling pathway. This was observed in tumorigenesis for human solid tumors, including hepatocellular carcinoma, melanoma, colon, ovarian and prostate cancer (66). Nuclear accumulation of $\beta$-catenin is linked with EMT in invasive colorectal tumors, and the association between the Wnt pathway and EMT has been investigated (67). Levels of ZEB1 expression have no influence on $\beta$-catenin/transcription factor 4 transcriptional signaling in colon cancer cell lines, although ZEB1 immunopositivity has been confirmed in non-invasive colon cancer cells and in tumor-associated fibroblasts (67). Furthermore, ZEB1 influenced the expression of other key proteins mediated by the Wnt signaling pathway, including membrane-type 1 matrix metalloproteinase and laminin gamma chain 2 (LAMC2) (59). Therefore, indicating that LAMC2 and all proteins mediated by the Wnt signaling pathway were implicated in the invasion and dissection of colorectal cancer cells (67). Additionally, in human meningioma tumor tissues, the expression of miR-200a was negatively associated with $\beta$-catenin and cyclin D1 (68). The aforementioned signals regulated by members of the miR-200 family in cancer are summarized in Fig. 2.

\section{Future directions and concerns}

Although much insight has been gained regarding the role of the miR-200 family in tumorigenesis and cancer progression, there is still a long way to go to fully comprehend and take advantage of miR utilizations in tumor therapeutics. Identifying unique patterns of deregulated expression of miR-200 family members may provide more significant information on the involvement of miR-200 family members in cancer. For example, miR-200 family members may act as molecular tumor markers for cancer initial diagnosis, confirm the degree of risk for cancer patients and to predict cancer prognosis and clinical responses to certain therapeutic strategies.

Furthermore, at the mechanistic level, despite some understanding of the miR-200/ZEB loop and signaling, further studies are required to define the elusive role of the miR-200 family in cancer pathogenesis, particularly in appropriate cellular and animal models. At the clinical level, further studies based on statistically valid experimental designs and selection of highly characterized case materials are required, which may identify the appropriate tumor marker and novel therapeutic strategies for improved cancer diagnosis and treatment.

In conclusion, tumor invasion and metastasis are responsible for cases of carcinoma-associated mortality. It is understood that EMT and tumor angiogenesis are critical steps in tumor invasion and metastasis. Therefore, targeting these processes may be a promising therapeutic strategy to treat cancer. Encouragingly, the miR-200 family members are key regulators of the epithelial phenotype, with targets involved in many aspects of EMT. In the future, improving understanding of the regulation and function of miR-200 family members in EMT, tumor angiogenesis and metastatic processes may aid 
in the development of a more effective method of attenuating cancer metastasis. Further understanding regarding the role of miR-200 in cancer progression and the development of more efficient miR regulatory molecules to treat cancer may vastly improve the clinical treatment of tumors.

\section{Acknowledgments}

The present study was supported by the National Natural Science Foundation (grant no. 81302250) and Tianjin Health Bureau of Science and Technology Funds (grant no. 2012KZ073).

\section{References}

1. Lee RC,Feinbaum RL and Ambros V:The C.elegans heterochronic gene lin-4 encodes small RNAs with antisense complementarity to lin-14. Cell 75: 843-854, 1993.

2. Bartel DP: MicroRNAs: Target recognition and regulatory functions. Cell 136: 215-233, 2009.

3. Sorek R and Cossart P: Prokaryotic transcriptomics: A new view on regulation, physiology and pathogenicity. Nat Rev Genet 11 : 9-16, 2010.

4. Esquela-Kerscher A and Slack FJ: Oncomirs-microRNAs with a role in cancer. Nat Rev Cancer 6: 259-269, 2006.

5. Tomasetti M, Lee W, Santarelli L and Neuzil J: Exosome-derived microRNAs in cancer metabolism: Possible implications in cancer diagnostics and therapy. Exp Mol Med 49: e285, 2017.

6. Paul P, Chakraborty A, Sarkar D, Langthasa M, Rahman M, Bari M, Singha RS, Malakar AK and Chakraborty S: Interplay between miRNAs and human diseases: A review. J Cell Physiol: Feb 9, 2017 (Epub ahead of print).

7. Meltzer PS: Cancer genomics: Small RNAs with big impacts. Nature 435: 745-746, 2005.

8. Chang CJ, Chao CH, Xia W, Yang JY, Xiong Y, Li CW, Yu WH, Rehman SK, Hsu JL, Lee HH, et al: p53 regulates epithelial-mesenchymal transition and stem cell properties through modulating miRNAs. Nat Cell Biol 13: 317-323, 2011.

9. Kim T, Veronese A, Pichiorri F, Lee TJ, Jeon YJ, Volinia S, Pineau P, Marchio A, Palatini J, Suh SS, et al: p53 regulates epithelial-mesenchymal transition through microRNAs targeting ZEB1 and ZEB2. J Exp Med 208: 875-883, 2011.

10. Humphries B and Yang C: The microRNA-200 family: Small molecules with novel roles in cancer development, progression and therapy. Oncotarget 6: 6472-6498, 2015.

11. Gregory PA, Bert AG, Paterson EL, Barry SC, Tsykin A, Farshid G, Vadas MA, Khew-Goodall Y and Goodall GJ: The miR-200 family and miR-205 regulate epithelial to mesenchymal transition by targeting ZEB1 and SIP1. Nat Cell Biol 10: 593-601, 2008.

12. Zidar N, Boštjančič E, Gale N, Kojc N, Poljak M, Glavač D and Cardesa A: Down-regulation of microRNAs of the miR-200 family and miR-205, and an altered expression of classic and desmosomal cadherins in spindle cell carcinoma of the head and neck-hallmark of epithelial-mesenchymal transition. Hum Pathol 42: 482-488, 2011.

13. Braun J, Hoang-Vu C, Dralle $H$ and Hüttelmaier $S$ : Downregulation of microRNAs directs the EMT and invasive potential of anaplastic thyroid carcinomas. Oncogene 29: 4237-4244, 2010.

14. Wiklund ED, Bramsen JB, Hulf T, Dyrskjøt L, Ramanathan R, Hansen TB, Villadsen SB, Gao S, Ostenfeld MS, Borre M, et al: Coordinated epigenetic repression of the miR-200 family and miR-205 in invasive bladder cancer. Int J Cancer 128: 1327-1334, 2011.

15. Aydoğdu E, Katchy A, Tsouko E, Lin CY, Haldosén LA, Helguero L and Williams C: MicroRNA-regulated gene networks during mammary cell differentiation are associated with breast cancer. Carcinogenesis 33: 1502-1511, 2012.

16. Lee JW, Park YA, Choi JJ, Lee YY, Kim CJ, Choi C, Kim TJ, Lee NW, Kim BG and Bae DS: The expression of the miRNA-200 family in endometrial endometrioid carcinoma. Gynecol Oncol 120: 56-62, 2011.

17. Du Y, Xu Y, Ding L, Yao H, Yu H, Zhou T and Si J: Down-regulation of miR-141 in gastric cancer and its involvement in cell growth. J Gastroenterol 44: 556-561, 2009.
18. Ladeiro Y, Couchy G, Balabaud C, Bioulac-Sage P, Pelletier L, Rebouissou S and Zucman-Rossi J: MicroRNA profiling in hepatocellular tumors is associated with clinical features and oncogene/tumor suppressor gene mutations. Hepatology 47: 1955-1963, 2008.

19. Pacurari M, Addison JB, Bondalapati N, Wan YW, Luo D, Qian Y, Castranova V, Ivanov AV and Guo NL: The microRNA-200 family targets multiple non-small cell lung cancer prognostic markers in H1299 cells and BEAS-2B cells. Int J Oncol 43: 548-560, 2013.

20. Wiklund ED, Gao S, Hulf T, Sibbritt T, Nair S, Costea DE, Villadsen SB, Bakholdt V, Bramsen JB, Sørensen JA, et al: MicroRNA alterations and associated aberrant DNA methylation patterns across multiple sample types in oral squamous cell carcinoma. PloS One 6: e27840, 2011.

21. Nam EJ, Yoon H, Kim SW, Kim H, Kim YT, Kim JH, Kim JW and Kim S: MicroRNA expression profiles in serous ovarian carcinoma. Clin Cancer Res 14: 2690-2695, 2008.

22. Gee GV, Koestler DC, Christensen BC, Sugarbaker DJ, Ugolini D, Ivaldi GP, Resnick MB, Houseman EA, Kelsey KT and Marsit CJ: Downregulated microRNAs in the differential diagnosis of malignant pleural mesothelioma. Int J Cancer 127: 2859-2869, 2010

23. Barron N, Keenan J, Gammell P, Martinez VG, Freeman A, Masters JR and Clynes M: Biochemical relapse following radical prostatectomy and miR-200a levels in prostate cancer. Prostate 72: 1193-1199, 2012.

24. Castro-Vega LJ, Jouravleva K, Liu WY, Martinez C, Gestraud P, Hupé P, Servant N, Albaud B, Gentien D, Gad S, et al: Telomere crisis in kidney epithelial cells promotes the acquisition of a microRNA signature retrieved in aggressive renal cell carcinomas. Carcinogenesis 34: 1173-1180, 2013.

25. Hur K, Toiyama Y, Takahashi M, Balaguer F, Nagasaka T, Koike J, Hemmi H, Koi M, Boland CR and Goel A: MicroRNA-200c modulates epithelial-to-mesenchymal transition (EMT) in human colorectal cancer metastasis. Gut 62: 1315-1326, 2013.

26. van Kempen LC, van den Hurk K, Lazar V, Michiels S, Winnepenninckx V, Stas M, Spatz A and van den Oord JJ: Loss of microRNA-200a and c, and microRNA-203 expression at the invasive front of primary cutaneous melanoma is associated with increased thickness and disease progression. Virchows Arch 461, 441-448, 2012.

27. Yu J, Ohuchida K, Mizumoto K, Sato N, Kayashima T, Fujita H, Nakata K and Tanaka M: MicroRNA, hsa-miR-200c, is an independent prognostic factor in pancreatic cancer and its upregulation inhibits pancreatic cancer invasion but increases cell proliferation. Mol Cancer 9: 169, 2010.

28. Xia H, Ng SS, Jiang S, Cheung WK, Sze J, Bian XW, Kung HF and Lin MC: miR-200a-mediated downregulation of ZEB2 and CTNNB1 differentially inhibits nasopharyngeal carcinoma cell growth, migration and invasion. Biochem Biophys Res Commun 391: 535-541, 2010.

29. Baer C, Claus R and Plass C: Genome-wide epigenetic regulation of miRNAs in cancer. Cancer Res 73: 473-477, 2013.

30. Pal MK, Jaiswar SP, Dwivedi VN, Tripathi AK, Dwivedi A and Sankhwar P: MicroRNA: A new and promising potential biomarker for diagnosis and prognosis of ovarian cancer. Cancer Biol Med 12: 328-341, 2015.

31. Azrak SS, Ginel-Picardo A, Drosten M, Barbacid M and Santos E: Reversible, interrelated mRNA and miRNA expression patterns in the transcriptome of Rasless fibroblasts: Functional and mechanistic implications. BMC Genomics 14: $731,2013$.

32. Siomi $H$ and Siomi MC: Posttranscriptional regulation of microRNA biogenesis in animals. Mol Cell 38: 323-332, 2010.

33. Browne G, Sayan AE and Tulchinsky E: ZEB proteins link cell motility with cell cycle control and cell survival in cancer. Cell Cycle 9: 886-891, 2010.

34. Gibbons DL, Lin W, Creighton CJ, Rizvi ZH, Gregory PA, Goodall GJ, Thilaganathan N, Du L, Zhang Y, Pertsemlidis A and Kurie JM: Contextual extracellular cues promote tumor cell EMT and metastasis by regulating miR-200 family expression. Genes Dev 23: 2140-2151, 2009.

35. Pożarowska D and Pożarowski P: The era of anti-vascular endothelial growth factor (VEGF) drugs in ophthalmology, VEGF and anti-VEGF therapy. Cent Eur J Immunol 41: 311-316, 2016.

36. Welti J, Loges S, Dimmeler S and Carmeliet P: Recent molecular discoveries in angiogenesis and antiangiogenic therapies in cancer. J Clin Invest 123: 3190-3200, 2013. 
37. Zhang HF, Xu LY and Li EM: A family of pleiotropically acting microRNAs in cancer progression, miR-200: Potential cancer therapeutic targets. Curr Pharm Des 20: 1896-1903, 2014.

38. Liu H, Brannon AR, Reddy AR, Alexe G, Seiler MW, Arreola A, Oza JH, Yao M, Juan D, Liou LS, et al: Identifying mRNA targets of microRNA dysregulated in cancer: With application to clear cell renal cell carcinoma. BMC Syst Biol 4: 51, 2010.

39. Choi YC, Yoon S, Jeong Y, Yoon J and Baek K: Regulation of vascular endothelial growth factor signaling by miR-200b. Mol Cells 32: 77-82, 2011

40. Roybal JD, Zang Y, Ahn YH, Yang Y, Gibbons DL, Baird BN, Alvarez C, Thilaganathan N, Liu DD, Saintigny P, et al: miR-200 inhibits lung adenocarcinoma cell invasion and metastasis by targeting Flt1/VEGFR1. Mol Cancer Res 9: 25-35, 2011.

41. Chan YC, Khanna S, Roy S and Sen CK: miR-200b targets Ets-1 and is down-regulated by hypoxia to induce angiogenic response of endothelial cells. J Biol Chem 286: 2047-20156, 2011.

42. Chan YC, Roy S, Khanna S and Sen CK: Downregulation of endothelial microRNA-200b supports cutaneous wound angiogenesis by desilencing GATA binding protein 2 and vascular endothelial growth factor receptor 2. Arterioscler Thromb Vasc Biol 32: 1372-1382, 2012.

43. Pecot CV, Rupaimoole R, Yang D, Akbani R, Ivan C, Lu C, Wu S, Han HD, Shah MY, Rodriguez-Aguayo C, et al: Tumour angiogenesis regulation by the miR-200 family. Nat Commun 4: 2427, 2013.

44. Knezevic J, Pfefferle AD, Petrovic I, Greene SB, Perou CM and Rosen JM: Expression of miR-200c in claudin-low breast cancer alters stem cell functionality, enhances chemosensitivity and reduces metastatic potential. Oncogene 34: 5997-6006, 2015.

45. Rossi L, Bonmassar E and Faraoni I: Modification of miR gene expression pattern in human colon cancer cells following exposure to 5-fluorouracil in vitro. Pharmacol Res 56: 248-253, 2007.

46. Pogribny IP, Filkowski JN, Tryndyak VP, Golubov A, Shpyleva SI and Kovalchuk O: Alterations of microRNAs and their targets are associated with acquired resistance of MCF-7 breast cancer cells to cisplatin. Int J Cancer 127: 1785-1794, 2010.

47. Rui W, Bing F, Hai-Zhu S, Wei D and Long-Bang C: Identification of microRNA profiles in docetaxel-resistant human non-smal cell lung carcinoma cells (SPC-A1). J Cell Mol Med 14: 206-214, 2010.

48. Chen DQ, Pan BZ, Huang JY, Zhang K, Cui SY, De W, Wang R and Chen LB: HDAC 1/4-mediated silencing of microRNA-200b promotes chemoresistance in human lung adenocarcinoma cells. Oncotarget 5: 3333-3349, 2014

49. Kinose Y, Sawada K, Nakamura K and Kimura T: The role of microRNAs in ovarian cancer. Biomed Res Int 2014: 249393, 2014.

50. Park SM, Gaur AB, Lengyel E and Peter ME: The miR-200 family determines the epithelial phenotype of cancer cells by targeting the E-cadherin repressors ZEB1 and ZEB2. Genes Dev 22: 894-907, 2008

51. Korpal M, Lee ES, Hu G and Kang Y: The miR-200 family inhibits epithelial-mesenchymal transition and cancer cell migration by direct targeting of E-cadherin transcriptional repressors ZEB1 and ZEB2. J Biol Chem 283: 14910-14914, 2008.

52. Winkler F, Kozin SV, Tong RT, Chae SS, Booth MF, Garkavtsev I, Xu L, Hicklin DJ, Fukumura D, di Tomaso E, et al: Kinetics of vascular normalization by VEGFR2 blockade governs brain tumor response to radiation: Role of oxygenation, angiopoietin-1, and matrix metalloproteinases. Cancer Cell 6: 553-563, 2004.

53. Thomas S, Quinn BA, Das SK, Dash R, Emdad L, Dasgupta S, Wang XY, Dent P, Reed JC, Pellecchia M, et al: Targeting the Bcl-2 family for cancer therapy. Expert Opin Ther Targets 17: $61-75,2013$
54. Kurashige J, Kamohara H, Watanabe M, Hiyoshi Y, Iwatsuki M, Tanaka Y, Kinoshita K, Saito S, Baba Y and Baba H: MicroRNA-200b regulates cell proliferation, invasion, and migration by directly targeting ZEB2 in gastric carcinoma. Ann Surg Oncol 19 (Suppl 3): S656-S664, 2012.

55. Leskelä S, Leandro-García LJ, Mendiola M, Barriuso J, Inglada-Pérez L, Muñoz I, Martínez-Delgado B, Redondo A, de Santiago J, Robledo M, et al: The miR-200 family controls beta-tubulin III expression and is associated with paclitaxel-based treatment response and progression-free survival in ovarian cancer patients. Endocr Relat Cancer 18: 85-95, 2011.

56. Xia W, Li J, Chen L, Huang B, Li S, Yang G, Ding H, Wang F, Liu N, Zhao Q, et al: MicroRNA-200b regulates cyclin D1 expression and promotes S-phase entry by targeting RND3 in HeLa cells. Mol Cell Biochem 344, 261-266, 2010.

57. Koutsaki M, Spandidos DA and Zaravinos A: Epithelial-mesenchymal transition-associated miRNAs in ovarian carcinoma, with highlight on the miR-200 family: Prognostic value and prospective role in ovarian cancer therapeutics. Cancer Lett 351: 173-181, 2014

58. Feng X, Wang Z, Fillmore R and Xi Y: MiR-200, a new star miRNA in human cancer. Cancer Lett 344: 166-173, 2014.

59. Hill L, Browne G and Tulchinsky E: ZEB/miR-200 feedback loop: At the crossroads of signal transduction in cancer. Int $\mathrm{J}$ Cancer 132, 745-754, 2013.

60. Yang Y, Ahn YH, Gibbons DL, Zang Y, Lin W, Thilaganathan N, Alvarez CA, Moreira DC, Creighton CJ, Gregory PA, et al: The Notch ligand Jagged2 promotes lung adenocarcinoma metastasis through a miR-200-dependent pathway in mice. J Clin Invest 121: 1373-1385, 2011

61. Ahn SM, Cha JY, Kim J, Kim D, Trang HT, Kim YM, Cho YH, Park D and Hong S: Smad3 regulates E-cadherin via miRNA-200 pathway. Oncogene 31: 3051-3059, 2012

62. Zhou X, Wang Y, Shan B, Han J, Zhu H, Lv Y, Fan X, Sang M, Liu XD and Liu W: The downregulation of miR-200c/141 promotes ZEB1/2 expression and gastric cancer progression. Med Oncol 32: 428, 2015.

63. Argast GM, Krueger JS, Thomson S, Sujka-Kwok I, Carey K Silva S, O'Connor M, Mercado P, Mulford IJ, Young GD, et al: Inducible expression of TGF $\beta$, snail and Zeb1 recapitulates EMT in vitro and in vivo in a NSCLC model. Clin Exp Metastasis 28 , 593-614, 2011.

64. Brabletz S, Bajdak K, Meidhof S, Burk U, Niedermann G, Firat E, Wellner U, Dimmler A, Faller G, Schubert J and Brabletz T: The ZEB1/miR-200 feedback loop controls Notch signalling in cancer cells. EMBO J 30: 770-782, 2011.

65. Sánchez-Tilló E, de Barrios O, Valls E, Darling DS, Castells A and Postigo A: ZEB1 and TCF4 reciprocally modulate their transcriptional activities to regulate Wnt target gene expression. Oncogene 34: 5760-5770, 2015.

66. Zaravinos A: The regulatory role of microRNAs in EMT and cancer. J Oncol 2015: 865816, 2015.

67. Kahlert C, Lahes S, Radhakrishnan P, Dutta S, Mogler C, Herpel E, Brand K, Steinert G, Schneider M, Mollenhauer M, et al: Overexpression of ZEB2 at the invasion front of colorectal cancer is an independent prognostic marker and regulates tumor invasion in vitro. Clin Cancer Res 17: 7654-7663, 2011.

68. Saydam O, Shen Y, Würdinger T, Senol O, Boke E, James MF, Tannous BA, Stemmer-Rachamimov AO, Yi M, Stephens RM, et al: Downregulated microRNA-200a in meningiomas promotes tumor growth by reducing E-cadherin and activating the Wnt/beta-catenin signaling pathway. Mol Cell Biol 29: 5923-5940, 2009. 